ISSN 2077-1827. Гуманізація навчально-виховного процесу. 2019, №. 6 (98)

РОЗДІЛ. ВИЩА ШКОЛА

УДК 378.14.015.62

\title{
КОШЕВА Людмила
}

канд. пед. наук, доцент, доцент кафедри фізичного виховання і спорту, Донбаська державна машинобудівна академія

вул. Академічна, 72, м.Краматорськ, Донецька обл., Україна, 84313

E-mail: kosheva@,i.ua

\section{КОВАЛЕВСЬКИЙ Сергій}

д-р техн. наук, професор, завідувач кафедри технології машинобудування, Донбаська державна машинобудівна академія

вул. Академічна, 72, м.Краматорськ, Донецька обл., Україна, 84313

E-mail: kovalevskii@dgma.donetsk.ua

\section{КОВАЛЕВСЬКА Олена}

канд. техн. наук, доцент, доцент кафедри комп'ютеризованого дизайну і моделювання процесів і машин, Донбаська державна машинобудівна академія вул. Академічна, 72, м.Краматорськ, Донецька обл., Україна, 84313

E-mail: olenakovalevskaya@gmail.com

\section{КОМПЕТЕНТНІСНО-ЦІННІСНЕ МОДЕЛЮВАННЯ ВИКОРИСТАННЯМ НЕЙРОМЕРЕЖНОГО БАЗІСУ}

Анотація. В роботі показано, що складові особистісної підсистеми моделі процесу підготовки фахівця дозволяють реалізувати у нього важливі аспекти видів професійної діяльності, розв'язуваних завдань і необхідних компетенцій. Тому, система сформованих особистісних цінностей $\epsilon$ визначальною умовою досягнення необхідних професійних якостей майбутнього фахівця. При цьому, компетентнісна складова моделі діяльності тісно пов'язана 3 характеристикою зовнішнього середовища моделі особистості. Представлена концептуальна модель, що припускає адаптивне формування етапів процесу підготовки фахівця до умов освітнього процесу, що впливає на змістовні параметри навчання, що, безсумнівно, визначає таку складову моделі системи особистісних якостей, як ступінь реалізації цілей. Для ефективного визначення цієї моделі часто, єдино можливим засобом дослідження i застосування в практичних цілях знань про особливості модельованих об'єктів $є$ математичне моделювання, для якого центральним поняттям теорії математичного моделювання $є$ поняття адекватності. Показано, що аргументована перевірка адекватності моделі забезпечує отримання добротних i практично значущих результатів. Для визначення адекватності математичної моделі реальному процесу запропоновано за допомогою нейронних мереж порівняти одержані в ході експериментальних досліджень величини 3 прогнозами при певних параметрах процесу. Авторами роботи вдалося встановити взаємозв'язок між навчальними i тестовими множинами при створенні адекватних моделей об'єктів різної (C) Кошева Л., Ковалевський С., Ковалевська О., 2019 
ISSN 2077-1827. Гуманізація навчально-виховного процесу. 2019, №. 6 (98)

РОЗДІЛ. ВИЩА ШКОЛА

природи з урахуванням найкращого поєднання повноти-точності створюваної моделі з одного боку і її простоти з іншого. Це виконано шляхом проведення оцінок точності-адекватності нейромережних моделей на основі варіювання випадкових виборів навчальних і тестових підмножин, сформованих з одного i того ж масиву даних, доступних для створення нейромережной моделі. В роботі доведено, що для нейромережних моделей адекватність і точність досягаються при $30 \%$ частці тестовій множини. 3 урахуванням цього запропоновано адаптивну модель процесу підготовки фахівця 3 використанням нейромережного базису.

Ключові слова: компетентність, особистісні цінності, педагогічні технології, нейронні мережі, адекватність моделювання, система.

Постановка проблеми у загальному вигляді та її зв'язок 3 важливими науковими і практичними завданнями. Основним суб'єктом педагогічної технології процесу підготовки випускників вишу є викладач, що є носієм змісту освітнього процесу, організатором педагогічних умов, що забезпечують досягнення результатів, у тому числі - ціннісну орієнтацію випускників вишу. Також, в особистості викладача концентрується сукупність його цінностей, що проявляються в реалізованій ним педагогічній технології. Таким чином, викладач, будучи носієм ціннісного потенціалу, трансформує ці цінності у свідомість студентів через навчальний процес. Викладач $\epsilon$ i суб'єктом технологічного процесу, і його організатором. Урахування індивідуальних особливостей студентів, вирішення освітньо-виховних завдань, урахування інтересів студентів, різноманітність, новизна, емоційність занять, а також загальнокультурний рівень, ерудиція, наукова й методична підготовка, відповідальність, працьовитість, переконаність, розумна вимогливість, педагогічна майстерність викладача $\epsilon$ умовами, що забезпечують якість виховного процесу [1].

Для успіху навчально-виховного процесу значимим $є$ те ставлення до формування компетентностей майбутніх фахівців, що грунтується на внутрішніх потребах, мотивах студентів, а також на сукупності засвоєних ними знань, умінь і навичок професійної діяльності. У такому

підході зіштовхуються дві альтернативні можливості - формування компетентностей майбутніх бакалаврів i магістрів в групових заняттях i індивідуальне формування особистісних властивостей кожного студента тобто - системи його особистісних цінностей $[1,2,3,3]$. При тому, створення формалізованих моделей, що дозволяють порівнювати різні підходи до формування системи компетенцій $\mathrm{i}$ цінностей майбутніх фахівців $\epsilon$ актуальною проблемою.

Аналіз останніх досліджень і публікацій, в яких започатковано розв'язання даної проблеми і на які спирасться автор, виділення невирішених раніше частин загальної проблеми, котрим присвячусться означена стаття. Важливо зрозуміти, яким чином людина мотивується в діяльності, спрямованій на досягнення успіхів і як вона реагує на невдачі, що трапляються. Умови досягнення успіхів і попередження невдач важливі види людської мотивації, від яких залежать доля й стан людини 
ISSN 2077-1827. Гуманізація навчально-виховного процесу. 2019, №. 6 (98)

РОЗДІЛ. ВИЩА ШКОЛА

в суспільстві [5, 5]. Безумовно, мета підготовки й сукупність психологопедагогічних настанов дозволяють сформувати зміст підготовки фахівця, включаючи іï акмеологічні і аксіологічні аспекти $[3,7]$. Уже на цьому етапі повинні бути визначені вимоги до професіоналізму, а також ціннісна система координат фахівця. Стан і перспективи компетентнісного підходу в сучасній освіті, проблематику цінності та формуванню ціннісних орієнтацій досліджували вчені Бех І., Бібік Н., Болгаріна В., Ващенко Л., Григор'єва В., Сльникова Г., Гуцан Л., Єрмаков І., Локшина О., Несен Г..Овчарук О., Паращенко Л., Пометун О., Рижикова В., Родніна І., Савченко О., Свистун В., Сохань Л., Трубачева С. та інші. Ці роботи є основою моделі фахівця як сукупності знань про шляхи вирішення поставлених завдань, умінь і навичок професійної діяльності.

Формулювання цілей статті (постановка завдання). Основною ціллю статті є обгрунтування шляхів підвищення адекватності математичних моделей, побудованих на нейромережному базисі, що відображають процеси формування компетенцій і ціннісних якостей майбутніх фахівців.

Виклад основного матеріалу дослідження 3 повним обгрунтуванням отриманих наукових результатів. В процесі формування фахівця найважливіше значення мають виховна діяльність й психолого-педагогічна підтримка розвитку особистості. Саме ці складові особистісної підсистеми моделі процесу підготовки фахівця дозволяють реалізувати у нього аспекти, позначені нами в моделі діяльності: переліки сфер, об'єктів, видів професійної діяльності, розв'язуваних завдань і необхідних компетенцій.

Як видно 3 наведеного переліку, система формованих цінностей $€$ визначальною умовою досягнення необхідних професійних якостей майбутнього фахівця [7, 9]. При цьому, компетентнісна складова моделі діяльності тісно пов'язана з характеристикою зовнішнього середовища моделі особистості. У цьому випадку організація-стейкхолдер є замовником фахівця, пред'являючи до нього систему вимог до компетенцій.

Концептуальна модель підготовки фахівця у вищому навчальному закладі включає чотири основні блоки (див. рис.1).

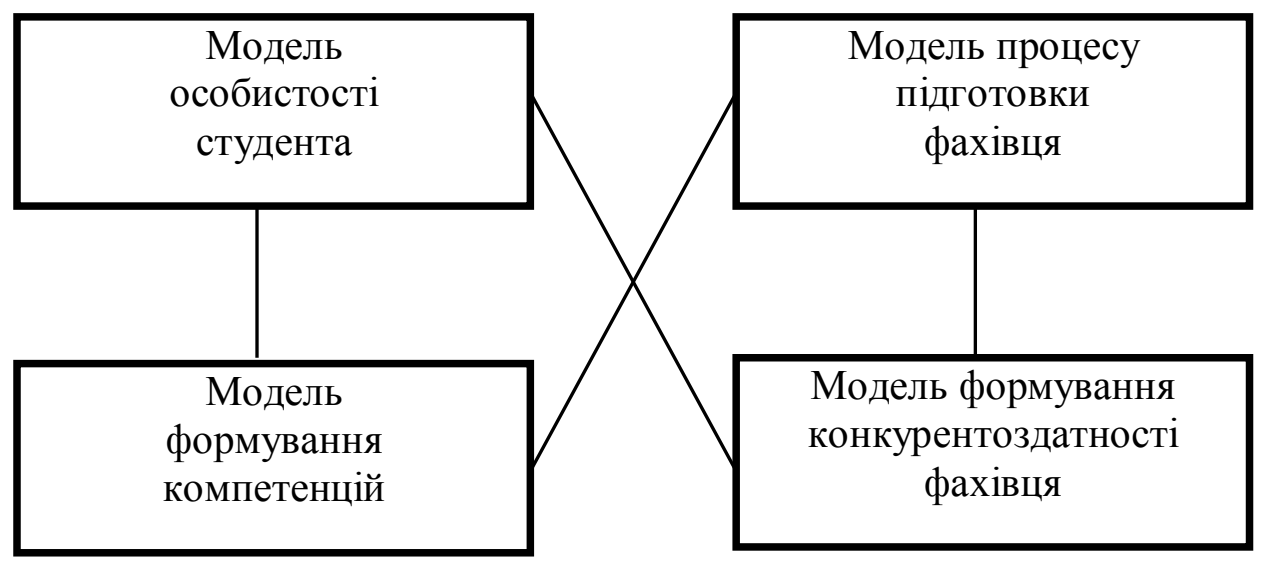

Рис. 1 - Концептуальна модель підготовки фахівця • 
В ідеальному випадку концептуальна модель припускає адаптивне формування етапів процесу підготовки фахівця до умов освітнього процесу, що впливає на змістовні параметри навчання, що, безсумнівно, визначає таку складову моделі системи особистісних якостей, як ступінь реалізації цілей. Одночасно формується система компетенцій фахівця, технології навчання, засоби й методи їх досягнень. Кожна $з$ представлених складових концептуальної моделі компетенцій $\epsilon$ комплексною, що припускає значну самостійну роботу студента. Тут слід зазначити особливу важливість узгодження вимог до компетенцій, яке повинно здійснюватися на початковому етапі їхніх формувань. Але, більш важливим є визначення кількісних оцінок взаємозв'язку факторів, що $є$ впливовими, 3 метою використання їх для оптимального управління процесом досягнення певних компетенцій майбутніх фахівців. Такий підхід залишається актуальним для будь-якої фахової спрямованості освітнього процесу у вищих навчальних закладах. Тому, математичне моделювання об'єктів $є$ необхідним i, часто, єдино можливим засобом дослідження і застосування в практичних цілях знань про особливості модельованих об'єктів.

Центральним поняттям теорії моделювання $є$ поняття адекватності. Аргументована перевірка адекватності забезпечує отримання добротних i практично значущих результатів. Адекватність математичної моделі - це відповідність результатів обчислювального експерименту поведінки реального об'єкта. Цю відповідність слід оцінювати 3 точки зору цілей дослідження [10]. Тому можливі різні підходи до оцінки адекватності різних моделей. Для виявлення цієї відповідності для процесів, що характеризуються вимірними величинами - параметрами - необхідно проводити порівняння параметрів моделі і оригіналу в одних i тих же умовах. Питання про необхідну i достатню ступінь відповідності об'єкту - оригіналу або адекватності моделі відноситься до числа найважливіших у сфері модельної методології, а відповідь на це питання характеризує ефективність моделювання, яка відображає практичну корисність моделі. Тому порівнювати слід лише відповідні один одному параметри між собою і тільки в тій області функціонування об'єкта, в якій передбачається його досліджувати. Для визначення адекватності математичної моделі реальному процесу необхідно порівняти одержані в ході експерименту величини 3 прогнозами по моделі при певних параметрах процесу.

При моделюванні будь-якого об'єкту завжди прагнуть до максимально повного і точного відтворення в моделі властивостей і характеристик об'єкта. Наслідком цього є зростання складності моделі, яка проявляється в числі змінних, зокрема враховуються зв'язки і впливи, підвищуються вимоги до точності вихідних даних. Визначити математичним шляхом найкраще поєднання повноти-точності створюваної моделі з одного боку і простоти 3 іншого, практично ніколи не вдається через формалізацію і неоднозначність факторів, що підлягають врахуванню. Вирішальним фактором ефективності виявляється математичний апарат. При цьому, найкращу якість або ефективність будь-якої моделі досягається як розумний компроміс між 
ISSN 2077-1827. Гуманізація навчально-виховного процесу. 2019, №. 6 (98)

РОЗДІЛ. ВИЩА ШКОЛА

близькістю моделі до оригіналу (адекватністю) і простотою, що забезпечує можливість і зручність використання моделі за іiі прямим призначенням, а зайва точність моделі на практиці не менш шкідлива, ніж їі неповнота [11] .

Несуперечливість увазі, ідентичний характер зміни відповідних параметрів, тобто ідентичний вигляд основних властивостей функціональних залежностей на окремих ділянках, як-то: зростання, спадання, екстремуми, опуклість і т.ін.. При більш глибокому розгляді цього поняття стає очевидним різноманіття можливих критеріїв перевірки несуперечності. Оскільки порівнювані параметри в області функціонування об'єкта можуть приймати множину різних значень, остільки будь-які висновки про відповідність їх поведінки можна зробити тільки на підставі статистичної обробки таких множин. Тому адекватність перевіряється за допомогою статистичних критеріїв, які можуть 3 певною ймовірністю свідчити про відповідність результатів обчислювального експерименту поведінки реального об'єкта у відповідних умовах.

Математичні моделі складних систем i процесів будуються в основному як подібні детерміновані моделі, що володіють загальним 3 оригіналом математичним описом. Тому для адекватності математичної моделі поведінки оригіналу досить переконатися у виконанні двох властивостей: точності і несуперечності. Точність в задачах моделювання означає, що узагальнена характеристика неузгодженості відповідного параметра моделі і оригіналу повинна бути не більше, ніж заздалегідь задане значення прийнятною похибки. 3 урахуванням викладеного за такою характеристикою може виступати найбільше по модулю значення неузгодженості, середнє значення неузгодженості або статистична оцінка.

При ідентифікації слабко формалізованих складних систем, коли для побудови математичних моделей застосовуються штучні нейронні мережі, використання статистичних критеріїв іноді неможливо [10, 12].

Підхід, заснований на нейромережному базисі, являє собою математичні конструкції зі змінною структурою, яка залежить від вхідних даних. Перебудова структури елементів таких конструкцій відбувається за допомогою настроюються порогових елементів, рівень збудження яких залежить від вхідних даних. Перевірка адекватності таких моделей здійснюється на основі задовільного тестування на тестовій множині, яке не входить в навчальну множину, а об'єм масивів вихідних даних безпосередньо пов'язаний з якістю моделей, сформованих на основі цих даних.

Мета дослідження: встановити взаємозв'язок між навчальними i тестовими множинами при створенні адекватних моделей об'єктів різної природи.

$\mathrm{Y}$ загальному вигляді деякій векторній множині $\mathrm{X}$, яке може бути представлена n параметрами табл. 1 . 
ISSN 2077-1827. Гуманізація навчально-виховного процесу. 2019, №. 6 (98) РОЗДІЛ. ВИЩА ШКОЛА

Табличя 1

Кортежи прецедентів вихідних даних для моделювання

\begin{tabular}{|c|c|c|c|c|c|c|c|c|}
\hline № & $\mathrm{X}_{1}$ & $\mathrm{X}_{2}$ & $\mathrm{X}_{\mathrm{a}}$ & $X_{4}$ & $x$ & $\mathrm{X}_{6}$ & $\ldots$ & $X_{\mathrm{n}}$ \\
\hline 1 & $x_{11}$ & $x_{21}$ & $x_{31}$ & $x_{41}$ & $x_{51}$ & $x_{61}$ & $\ldots$ & $x_{n 1}$ \\
\hline 2 & $x_{12}$ & $x_{22}$ & $x_{32}$ & $x_{42}$ & $x_{52}$ & $x_{62}$ & $\ldots$ & $x_{n 2}$ \\
\hline 3 & $x_{13}$ & $x_{32}$ & $x_{33}$ & $x_{43}$ & $x_{53}$ & $x_{69}$ & $\ldots$ & $x_{\mathbf{n} 3}$ \\
\hline$\ldots$ & ... & $\ldots$ & $\ldots$ & $\ldots$ & ... & $\ldots$ & $\ldots$ & $\ldots$ \\
\hline $\mathrm{m}$ & $x_{1 m}$ & $x_{2 m}$ & $x_{\mathrm{Im}}$ & $x_{4 m}$ & $x_{5 m}$ & $x_{6 m}$ & $\ldots$ & $x_{m m}$ \\
\hline
\end{tabular}

Відповідно до поставленої мети дослідити особливості вибору навчального $\mathrm{Y}$ i тестового $\mathrm{Z}$ множин, коли $\mathrm{X} \ni \mathrm{Y}, \mathrm{Z}$, була сформована таблиця прецедентів (табл.2).

Таблиияя 2

Приклад кортежей прецедентів, що використовусться для нейромережного моделювання

\begin{tabular}{|r|c|c|c|c|c|c|c|c|c|c|c|c|c|}
\hline № & $\mathbf{x 1}$ & $\mathbf{x 2}$ & $\mathbf{x 3}$ & $\mathbf{x 4}$ & $\mathbf{x 5}$ & $\mathbf{x 6}$ & $\mathbf{x 7}$ & $\mathbf{x 8}$ & $\mathbf{x 9}$ & $\mathbf{x 1 0}$ & $\mathbf{x 1 1}$ & $\mathbf{x 1 2}$ & $\mathbf{Y}$ \\
\hline $\mathbf{1}$ & 1 & 0 & 1 & 1 & 0 & 0 & 1 & 0 & 1 & 0 & 0 & 0 & 2 \\
\hline $\mathbf{2}$ & 0 & 0 & 0 & 0 & 1 & 0 & 0 & 1 & 1 & 0 & 0 & 0 & 1 \\
\hline $\mathbf{3}$ & 1 & 1 & 1 & 0 & 0 & 0 & 1 & 1 & 1 & 0 & 1 & 0 & 1 \\
\hline $\mathbf{4}$ & 1 & 1 & 0 & 0 & 1 & 0 & 1 & 0 & 0 & 0 & 1 & 0 & 1 \\
\hline $\mathbf{5}$ & 1 & 1 & 0 & 1 & 0 & 1 & 0 & 0 & 0 & 1 & 0 & 0 & 2 \\
\hline $\mathbf{6}$ & 1 & 0 & 0 & 1 & 0 & 0 & 1 & 1 & 0 & 0 & 0 & 0 & 1 \\
\hline $\mathbf{7}$ & 1 & 0 & 0 & 1 & 0 & 0 & 1 & 0 & 1 & 0 & 1 & 0 & 2 \\
\hline $\mathbf{8}$ & 0 & 0 & 0 & 0 & 1 & 0 & 0 & 0 & 0 & 0 & 0 & 0 & 1 \\
\hline $\mathbf{9}$ & 0 & 0 & 1 & 0 & 1 & 0 & 0 & 1 & 1 & 0 & 0 & 1 & 2 \\
\hline $\mathbf{1 0}$ & 0 & 0 & 0 & 1 & 0 & 1 & 0 & 1 & 1 & 0 & 1 & 0 & 2 \\
\hline $\mathbf{1 1}$ & 0 & 1 & 0 & 0 & 1 & 0 & 1 & 0 & 0 & 0 & 0 & 1 & 1 \\
\hline $\mathbf{1 2}$ & 1 & 1 & 0 & 0 & 1 & 0 & 0 & 0 & 0 & 0 & 1 & 0 & 1 \\
\hline $\mathbf{1 3}$ & 1 & 1 & 0 & 0 & 0 & 0 & 0 & 1 & 0 & 0 & 0 & 1 & 1 \\
\hline $\mathbf{1 4}$ & 1 & 1 & 1 & 1 & 1 & 0 & 1 & 0 & 0 & 0 & 0 & 0 & 2 \\
\hline $\mathbf{1 5}$ & 0 & 0 & 0 & 0 & 1 & 0 & 0 & 1 & 0 & 0 & 0 & 0 & 1 \\
\hline $\mathbf{1 6}$ & 1 & 0 & 0 & 1 & 0 & 0 & 0 & 1 & 1 & 0 & 0 & 0 & 2 \\
\hline $\mathbf{1 7}$ & 0 & 1 & 1 & 0 & 1 & 0 & 1 & 1 & 0 & 1 & 0 & 0 & 1 \\
\hline $\mathbf{1 8}$ & 1 & 1 & 0 & 0 & 0 & 0 & 1 & 0 & 0 & 0 & 0 & 0 & 1 \\
\hline $\mathbf{1 9}$ & 1 & 1 & 0 & 0 & 1 & 1 & 0 & 0 & 1 & 0 & 0 & 1 & 2 \\
\hline $\mathbf{2 0}$ & 0 & 1 & 0 & 0 & 1 & 1 & 1 & 1 & 0 & 0 & 1 & 0 & 1 \\
\hline $\mathbf{2 1}$ & 1 & 1 & 0 & 0 & 1 & 1 & 1 & 1 & 0 & 0 & 1 & 0 & 1 \\
\hline $\mathbf{2 2}$ & 1 & 1 & 0 & 0 & 1 & 0 & 1 & 1 & 0 & 0 & 1 & 0 & 1 \\
\hline $\mathbf{2 3}$ & 1 & 1 & 1 & 0 & 1 & 0 & 0 & 1 & 0 & 0 & 0 & 0 & 1 \\
\hline $\mathbf{2 4}$ & 1 & 0 & 0 & 1 & 0 & 0 & 1 & 0 & 0 & 1 & 0 & 1 & 2 \\
\hline $\mathbf{2 5}$ & 0 & 1 & 0 & 0 & 1 & 0 & 0 & 0 & 0 & 0 & 1 & 0 & 1 \\
\hline $\mathbf{2 6}$ & 1 & 1 & 0 & 0 & 0 & 1 & 0 & 0 & 0 & 0 & 0 & 1 & 2 \\
\hline $\mathbf{2 7}$ & 0 & 0 & 0 & 0 & 1 & 0 & 1 & 0 & 0 & 0 & 0 & 0 & 1 \\
\hline
\end{tabular}


ISSN 2077-1827. Гуманізація навчально-виховного процесу. 2019, №. 6 (98)

РОЗДІЛ. ВИЩА ШКОЛА

\begin{tabular}{|l|l|l|l|l|l|l|l|l|l|l|l|l|l|}
\hline $\mathbf{2 8}$ & 1 & 1 & 1 & 1 & 0 & 0 & 1 & 1 & 1 & 0 & 0 & 0 & 2 \\
\hline $\mathbf{2 9}$ & 0 & 0 & 0 & 0 & 1 & 0 & 1 & 1 & 1 & 0 & 0 & 0 & 1 \\
\hline $\mathbf{3 0}$ & 1 & 1 & 0 & 1 & 1 & 0 & 0 & 0 & 0 & 1 & 0 & 0 & 2 \\
\hline $\mathbf{3 1}$ & 0 & 0 & 1 & 1 & 1 & 1 & 0 & 0 & 0 & 1 & 0 & 1 & 2 \\
\hline $\mathbf{3 2}$ & 0 & 1 & 1 & 1 & 1 & 1 & 0 & 1 & 1 & 1 & 0 & 0 & 2 \\
\hline
\end{tabular}

332 кортежів множини X (табл.2) були створені тестові вибірки, що представляють собою по 9 випадкових поєднань 39 рівнями обсягів тестових вибіркових масивів поєднань підмножин $\mathbf{Y}$ и $\mathbf{Z}: \mathrm{C}_{\mathbf{3 2}}^{\mathbf{3}} ; \mathrm{C}_{32}^{\mathbf{6}} ; \mathrm{C}_{32}^{9} ; \mathbf{C}_{\mathbf{3 2}}^{\mathbf{1 2}} ; \mathrm{C}_{\mathbf{3 2}}^{\mathbf{1 5}}$ $; \mathrm{C}_{32}^{18} ; \mathrm{C}_{32}^{21} ; \mathrm{C}_{32}^{24} ; \mathrm{C}_{32}^{27}$.

Методика досліджень включає проведення оцінок точностіадекватності нейромережних моделей на основі варіювання випадкових виборів навчальних і тестових підмножин, сформованих з одного і того ж масиву даних, доступних для створення нейромережной моделі. Методика порівняльного аналізу включала виконання наступних етапів:

1. Побудова нейромережних моделей на основі програмного пакету нейромережного моделювання та аналізу даних Neuro Pro 0,25 на основі даних навчальних підмножин Y.

2. Скорочення числа входів нейромережной моделі х1..x12, залишаючи тільки значущі для отримання заданої точності відтворення значень навчальних підмножин.

3. Тестування нейромережних моделей, отриманих в результаті виконання п.2, на тестових множини $\mathrm{Z}$ при одночасній оцінці точності тестування.

4. Побудова залежностей заданої точності навчання i отриманої точності тестування на множинах вибірок підмножин Y i Z масивів.

5. Аналіз отриманих результатів і розробка рекомендацій по методиці оцінки його нейромережевих моделей.

Таким чином було створено і проаналізовано 81 нейромережну модель із заданою похибкою моделювання $\pm 1,0 \%$. Результати тестування цих моделей представлені в табл. 3. 
ISSN 2077-1827. Гуманізація навчально-виховного процесу. 2019, №. 6 (98) РОЗДІЛ. ВИЩА ШКОЛА

Таблиия 3.

Похибки тестування 81 зразків нейромережних моделей

\begin{tabular}{|c|c|c|c|c|c|c|c|c|c|c|}
\hline \multirow{2}{*}{ 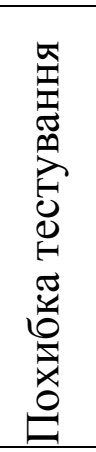 } & \multicolumn{8}{|c|}{ 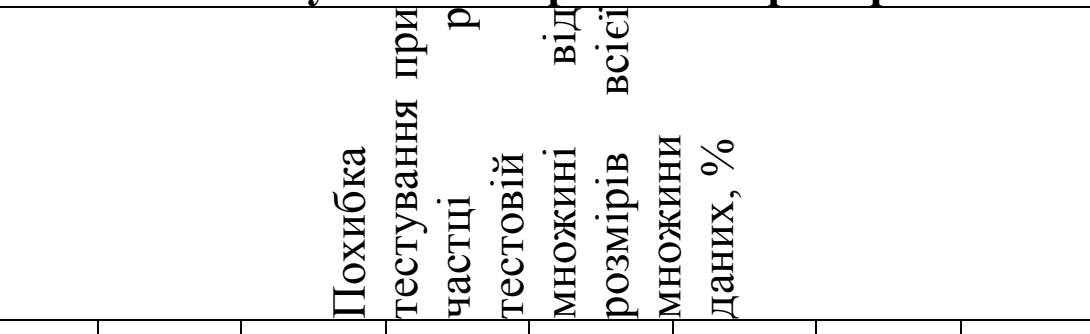 } & \multicolumn{2}{|c|}{ 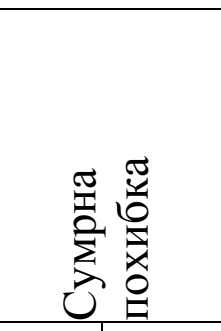 } \\
\hline & $\stackrel{ }{\circ}$ & 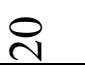 & ㅇ & $\stackrel{f}{\forall}$ & in & 8 & $\stackrel{2}{1}$ & $\infty$ & § & $\sim$ \\
\hline $\begin{array}{l}0 \\
8 \\
0 \\
0\end{array}$ & $\begin{array}{l}n \\
\tilde{n} \\
\hat{0}\end{array}$ & $\begin{array}{l}\bar{n} \\
\hat{0} \\
0\end{array}$ & $\begin{array}{l}\hat{\sigma} \\
\text { } \\
0\end{array}$ & $\begin{array}{l}\text { ํ. } \\
\delta \\
0\end{array}$ & $\hat{m}$ & $\begin{array}{l}\infty \\
\delta \\
\delta\end{array}$ & $\begin{array}{l}\text { ঠ } \\
8 \\
0\end{array}$ & $\begin{array}{l}n \\
\tilde{n} \\
\tilde{n}\end{array}$ & $\begin{array}{l}\infty \\
8 \\
\delta \\
0\end{array}$ & $\stackrel{\sqrt{N}}{\approx}$ \\
\hline $\begin{array}{l}\stackrel{0}{8} \\
8 \\
\dot{0}\end{array}$ & $\begin{array}{l}\text { ô } \\
\text { } \\
\text { రీ }\end{array}$ & $\begin{array}{l}0 \\
8 \\
0 \\
0\end{array}$ & $\hat{m}$ & $\frac{\mathfrak{a}}{\sigma^{\circ}}$ & $\stackrel{0}{m}$ & $\frac{8}{0}$ & $\frac{\bar{N}}{0}$ & $\frac{\mathbb{N}}{0}$ & $\begin{array}{l}2 \\
\text { mे } \\
\hat{\sigma}^{2}\end{array}$ & 8 \\
\hline $\begin{array}{l}\delta_{0}^{0} \\
8 \\
0 \\
0 \\
0\end{array}$ & $\frac{\infty}{\sigma^{\prime}}$ & $\frac{\infty}{a}$ & $\begin{array}{l}\infty \\
\wp \\
0\end{array}$ & 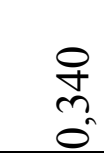 & \begin{tabular}{l}
0 \\
\multirow{j}{*}{} \\
0
\end{tabular} & $\frac{5}{\sigma_{0}}$ & $\frac{n}{7}$ & $\frac{8}{0}$ & $\begin{array}{l}n \\
8 \\
0 \\
0\end{array}$ & $\underset{\sim}{\stackrel{\sim}{\sim}}$ \\
\hline $\begin{array}{l}\stackrel{0}{0} \\
8 \\
8 \\
\dot{8}\end{array}$ & 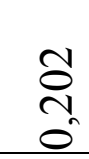 & $\frac{\stackrel{ \pm}{\sim}}{0^{\prime}}$ & $\frac{n}{\sigma}$ & $\frac{0}{\frac{1}{0}}$ & $\frac{9}{0}$ & $\frac{n}{\sigma}$ & $\begin{array}{l}8 \\
8 \\
0 \\
0\end{array}$ & $\frac{F}{0}$ & $\begin{array}{l}\hat{n} \\
\tilde{0} \\
0\end{array}$ & ñ \\
\hline $\begin{array}{l}80 \\
8 \\
8 \\
0 \\
0\end{array}$ & \begin{tabular}{l}
$\vec{\delta}$ \\
\multirow{0}{*}{} \\
$\sigma_{0}$
\end{tabular} & $\begin{array}{l}0 \\
\text { nn } \\
\sigma_{0}\end{array}$ & $\frac{\infty}{n}$ & $\frac{\infty}{n}$ & $\stackrel{\infty}{m}$ & $\frac{n}{\sqrt[n]{n}}$ & $\frac{1}{0}$ & $\frac{\stackrel{P}{ \pm}}{0^{0}}$ & $\begin{array}{l}n \\
\text { గn } \\
0\end{array}$ & ra \\
\hline $\begin{array}{l}80 \\
8 \\
8 \\
8\end{array}$ & $\frac{n}{0}$ & $\underset{\sigma}{\stackrel{\nabla}{+}}$ & $\frac{n}{\sigma}$ & $\begin{array}{l}\bar{\delta} \\
\tilde{0} \\
\delta\end{array}$ & $\frac{ \pm}{\sqrt{N}}$ & 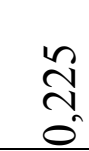 & 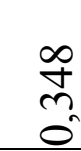 & $\begin{array}{l}8 \\
8 \\
n \\
0\end{array}$ & $\begin{array}{l}\tilde{n} \\
\text { nิ } \\
0\end{array}$ & 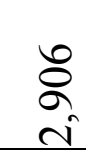 \\
\hline $\begin{array}{l}\stackrel{0}{8} \\
8 \\
0 \\
0\end{array}$ & $\frac{0}{0}$ & $\begin{array}{l}0 \\
6 \\
6 \\
0\end{array}$ & $\begin{array}{l}\hat{\infty} \\
\text { N } \\
\sigma^{\prime}\end{array}$ & 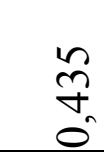 & $\frac{R}{0}$ & $\begin{array}{l}0 \\
\text { N } \\
\text { }\end{array}$ & ñ & $\begin{array}{l}\overline{0} \\
0 \\
0\end{array}$ & $\frac{N}{n}$ & $\begin{array}{l}0 \\
0 \\
0 \\
\text { N }\end{array}$ \\
\hline $\begin{array}{l}80 \\
8 \\
8 \\
0 \\
0\end{array}$ & 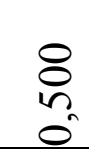 & $\frac{\sqrt[n]{n}}{\hat{0}}$ & $\begin{array}{l}n \\
\tilde{n} \\
\tilde{\sigma}\end{array}$ & $\frac{\hat{b}}{0}$ & $\hat{m}$ & $\begin{array}{l}0 \\
\text { m } \\
\mathfrak{n}^{2}\end{array}$ & $\frac{a}{n}$ & $\stackrel{\stackrel{+}{+}}{\overbrace{0}^{\circ}}$ & $\begin{array}{l}\infty \\
\text { ñ } \\
0^{n}\end{array}$ & $\bar{n}$ \\
\hline $\begin{array}{l}\stackrel{0}{8} \\
8 \\
8 \\
8\end{array}$ & \begin{tabular}{l}
$\infty$ \\
$\stackrel{\infty}{+}$ \\
\multirow{\sigma}{*}{}
\end{tabular} & $\vec{n}$ & $\frac{\bar{n}}{0}$ & $\tilde{m}_{0}$ & $\begin{array}{l}0 \\
\text { J } \\
0\end{array}$ & $\begin{array}{l}n \\
\tilde{n} \\
\tilde{n}\end{array}$ & $\frac{\vec{N}}{\sigma}$ & $\frac{n}{0}$ & $\begin{array}{c}\infty \\
\stackrel{\infty}{+} \\
0\end{array}$ & $\begin{array}{l}\infty \\
\text { ले } \\
\text { m. }\end{array}$ \\
\hline
\end{tabular}


ISSN 2077-1827. Гуманізація навчально-виховного процесу. 2019, №. 6 (98) РОЗДІЛ. ВИЩА ШКОЛА

На рис. 2 представлена графічна інтерпретація похибки $\mathrm{S}$ відтворення тестовій множини Z.

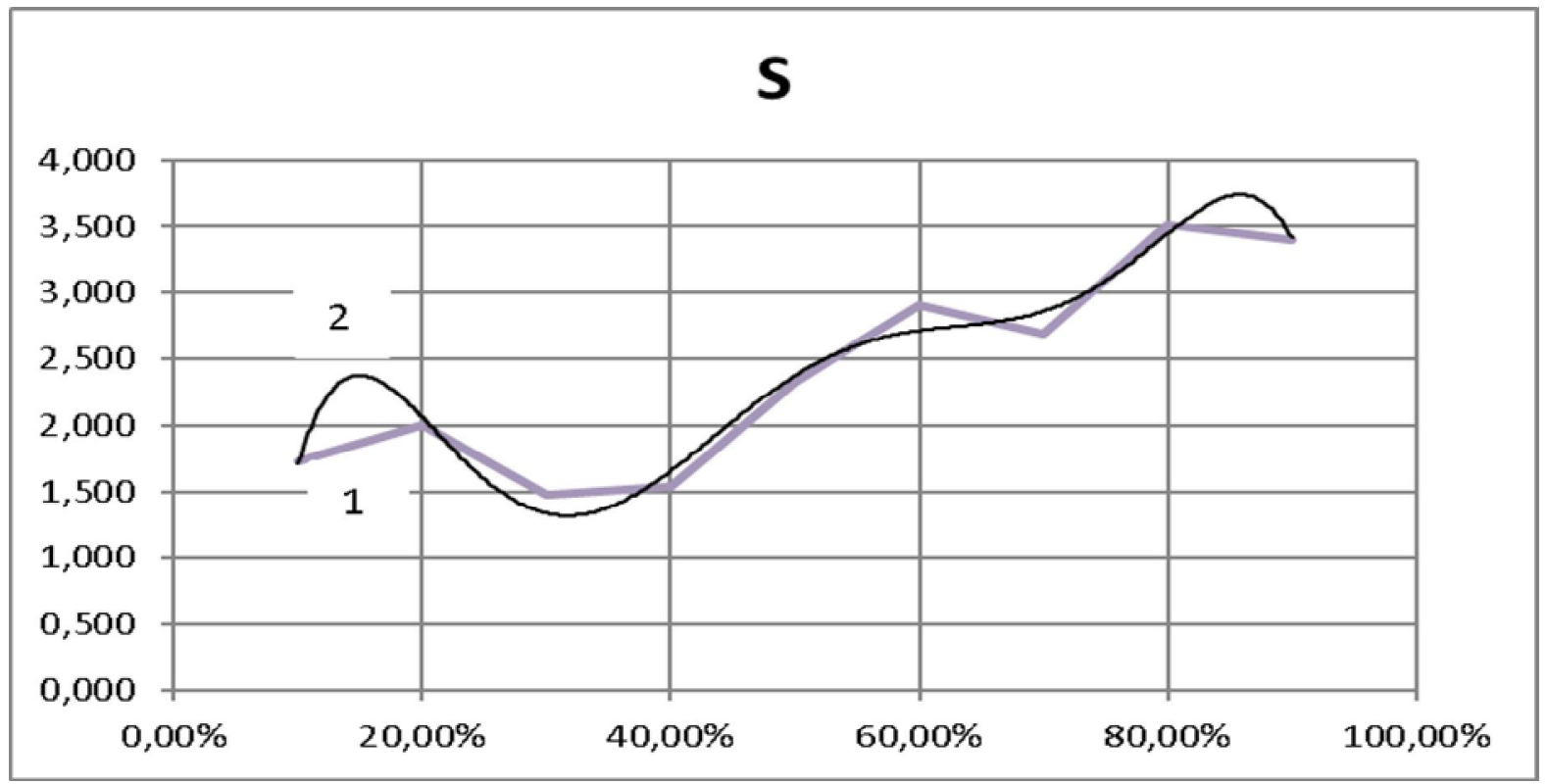

Рис. 2. Сумарна похибка 1 i ï̈ апроксимація поліномом двох варіантів тестування при частці тестовій множини від 10\% до 90\%.

Аналіз похибок моделювання і тестування моделей, представлений кривої тренду виду: $\mathbf{S}=-2219,9 \mathrm{p}^{6}+6889,8 \mathrm{p}^{5}-8388,4 \mathrm{p}^{4}+5041,9 \mathrm{p}^{3}-1535,2 \mathrm{p}^{2}+$ 216,97 p - 8,898 дозволив визначити мінімум похибки при $30 \ldots 35 \%$ частці тестової множини.

Вербальний опис оптимізованої моделі представлено наступним чином:

Database fields (initial symptoms):

$$
\begin{aligned}
& \mathrm{X} 4 \\
& \mathrm{X} 5 \\
& \mathrm{X} 8 \\
& \mathrm{X} 9 \\
& \mathrm{X} 12
\end{aligned}
$$

Database fields (end syndromes):

Y

Preprocessing the input fields of the database for supplying the network:

$$
\begin{aligned}
& \mathrm{X} 4=(\mathrm{X} 4-0,5) / 0,5 \\
& \mathrm{X} 5=(\mathrm{X} 5-0,5) / 0,5 \\
& \mathrm{X} 8=(\mathrm{X} 8-0,5) / 0,5 \\
& \mathrm{X} 9=(\mathrm{X} 9-0,5) / 0,5 \\
& \mathrm{X} 12=(\mathrm{X} 12-0,5) / 0,5
\end{aligned}
$$

Functional Converters:

Sigmoid_1 $(\mathrm{A})=\mathrm{A} /(0,1+|\mathrm{A}|)$

Level 1 syndromes: 
ISSN 2077-1827. Гуманізація навчально-виховного процесу. 2019, №. 6 (98)

РОЗДІЛ. ВИЩА ШКОЛА

Syndrome $1 \_$_ Sigmoid $1(0,5175867 * X 4-0,2253383 * X 5$ -

$0,7707164 * X 8+0,167638 * X 9-0,1165028 * X 12)$

Syndrome1_2=Sigmoid_1( $0,1908794 * X 8$ -

$0,09852738 * X 9+0,1385741 * \bar{X} 12-0,1664897)$

Syndrome1_3=Sigmoid_1( $0,3572189 * X 4+0,3209354 * X 12)$

Syndrome 1_4=Sigmoid_1( 0,6674076*X4-0,115299*X5-

$0,8144038 * \mathrm{X} 8+\mathrm{X} \overline{9}+0,184345 \overline{6} * \mathrm{X} 12+0,7063498)$

End-syndromes:

$\mathrm{Y}=0,6864882 *$ Syndrome1_1+Syndrome1_2-

$0,4366252 *$ Syndrome1_3+Syndrome1_4+0,3727925

Post-treatment of end-syndromes:

$\mathrm{Y}=\left(\left(\left(\mathrm{Y}^{*} 1\right)+3\right) / 2\right)$.

Мінімум сумарної похибки, яка оцінювалася щодо випадково сформованих підмножин $\mathbf{Y}$ и $\mathbf{Z}$ настав при встановленні тестової множини як $1 / 3$ випадково відібраної частини загального масиву даних, що використана для моделювання. Така рекомендація, безумовно, відрізняється від рекомендацій $80 \%$ / 20\% для часток підмножин Y i Z i повинна бути врахована при побудові нейромережних моделей. Саме така методика нейромережного моделювання пропонується для кількісної оцінки ефективності досягнення певних компетентностей при підготовки фахівців згідно системі, що відображена на рис.3.

Дослідження, результати яких представлені в статті, показали, що для нейромережних моделей адекватність і точність досягаються за умови формування навчальної і тестової вибірки, виходячи з досягнення задовільної точності при максимальному обсязі тестової вибірки. Тому, мінімум сумарної похибки при $30 \%$ частці тестовій множини свідчить про високу ймовірність впізнавання моделі. Мінімум сумарної похибки моделі на тестовому базісі повинен відповідати умові $\mathbf{S} \rightarrow \min ; \mathbf{p} \rightarrow \max$. Застосовуючи таке правило можна забезпечити точність i адекватність нейромережної моделі, грунтуючись на оптимальних навчальному і тестовому кортежах.

Попередні дослідження показали, що в результаті діагностики двох узагальнених стійких мотивів особистості - мотиву прагнення до успіху й мотиву попередження невдач, більш 60 \% опитаних, що займаються в експериментальному режимі, мають сформований мотив досягнення успіху i до $10 \%$ - мотив попередження невдач. У контрольних групах нижчий відсоток опитаних із мотивацією досягнення успіху - біля $25 \%$, до $30 \%$, мотивованих на невдачу. 
ISSN 2077-1827. Гуманізація навчально-виховного процесу. 2019, №. 6 (98) РОЗДІЛ. ВИЩА ШКОЛА

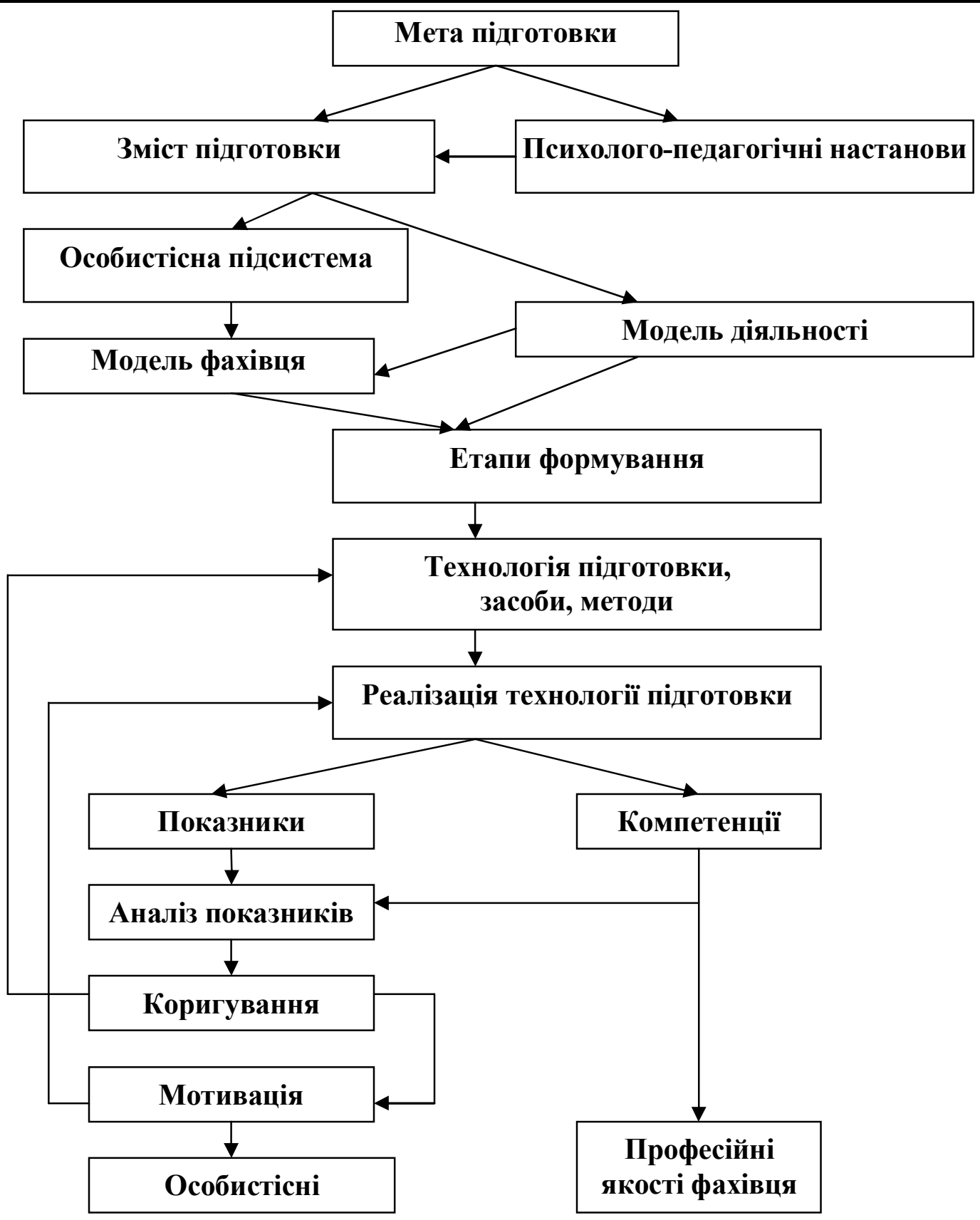

Рис. 3. Модель процесу підготовки фахівця 3 використанням нейромережного базису

Висновки 3 даного дослідження і перспективи подальших розвідок у даному напрямку. Підготовка фахівців, як система педагогічних технологій, впливає на формування мотиву досягнення успіху. Тому, велике значення має виявлення методів управління комплексом особистісних якостей студентів в групі підготовки фахівців через побудову та використання адекватних нейромережних моделей. Оцінювання ступеня досягнення результатів 3 формування необхідних компетенцій веде до необхідності своєчасної корекції технології освітньої діяльності. I тільки 
ISSN 2077-1827. Гуманізація навчально-виховного процесу. 2019, №. 6 (98)

РОЗДІЛ. ВИЩА ШКОЛА

достатня мотивація, заснована на духовному, соціальному й фізичному вихованні (вихованні культури) та на потребах особистості студента (модель особистості студента) дозволяє дійсно сформувати такі професійні якості фахівця, які дозволять у комплексі забезпечити відповідність підготовленого фахівця через його професійну діяльність.

\section{СПИСОК ВИКОРИСТАНОЇ ЛІТЕРАТУРИ}

1. Диба Т.Г. Феномен неперервної професійної освіти у досягненні професійного «акме». Освітологія, 2015. № 4. С. 30-36.

2. Компетентнісний підхід у сучасній освіті: світовий досвід та українські перспективи: колективна монографія. / Бібік І.М. та ін.; за заг.ред. О. В. Овчарук. Київ: К.І.С., 2004. 112 с.

3. Огнев'юк В.О. Освіта в системі цінностей сталого людського розвитку: монографія. Київ: Знання України, 2003. 448 с.

4. Освітологія: підготовка експертів у галузі освіти: навч.-метод. посіб. / ред. В.О. Огнев’юк. Київ: ТОВ ВП Едельвейс, 2015. 464 с.

5. Психологія діяльності та навчальний менеджмент: навч.-метод. посіб. / В. А. Козаков та ін. ; за заг. ред. В. А. Козакова. Київ: КНЕУ, 2003. 829 с.

6. Срмаков І.Г. Феномен компетентнісно спрямованої освіти. Крок за кроком до життєвої компетентності та успіху. Кіїв, ЛАТ \& К., 2003. $199 \mathrm{c}$.

7. Кабанкова О.М. Деякі аспекти акмеологічної компетентності майбутнього фахівця. Проблеми освіти: збірник наукових пращь. Житомир - Київ, 2015. Вип.84. С. 148-151.

8. Kovalevskyy S.V., Kosheva L.V. Study ofthe Nature and Structure of Corporate Culture with Neural Network Models. American Journal of Neural Networks and Applications. New York, 2015. Vol.1. No.1. P. 11-22.

9. Research the Corporate Culture of Students Using Neural Network Models. American Journal of Neural Networks and Applications. New York, 2015. Vol. 1. No. 2. P. 43-47.

10. Kaladze V.A. Mathematical models of casual processes with stationary increments and the non-uniform information dynamic processing. Monograph. Lorman, MS, USA: Science Book Publishing House, 2012. 136 p.

11.Ганцева Е.А., Каладзе В.А., Поляков А.М. Интеллектуальный критерий качества математических моделей сложных систем: идеология, перспективы разработки. Вестник Воронежского государственного технического университета. Воронеж, 2013. Т. 9. № 5.1. С. 52-56.

12. Kovalevskyy S., Kosheva L. Neural network's intellectual model of student. 12th International conference "Research and Development in Mechanical Industrry" RaDMI 2012, 13-17 September. Vrnjcka Banja, Serbia, 2012. Vol. 2. p. $779-786$.

Стаття надійшла до редакції 18.11.2019. 
ISSN 2077-1827. Гуманізація навчально-виховного процесу. 2019, №. 6 (98)

РОЗДІЛ. ВИЩА ШКОЛА

\section{КОШЕВАЯ Людмила}

канд. пед. наук, доцент, доцент кафедры физического воспитания и спорта, Донбасская государственная машиностроительная академия

ул. Академическая, 72, г.Краматорск, Донецкая обл., Украина, 84313

E-mail: kosheva@i.ua

\section{КОВАЛЕВСКИЙ Сергей}

д-р техн. наук, профессор, заведующий кафедрой технологии машиностроения, Донбасская государственная машиностроительная академия ул. Академическая, 72, г.Краматорск, Донецкая обл., Украина, 84313 E-mail: kovalevskii@dgma.donetsk.ua

\section{КОВАЛЕВСКАЯ Елена}

канд. техн. наук, доцент, доцент кафедры компьютеризированного дизайна и моделирования процессов и машин, Донбасская государственная машиностроительная академия

ул. Академическая, 72, г.Краматорск, Донецкая обл., Украина, 84313

E-mail: olenakovalevskaya@,gmail.com

КОМПЕТЕНТНОСТНО - ЦЕННОСТНОЕ МОДЕЛИРОВАНИЕ С ПРИМЕНЕНИЕМ НЕЙРОСЕТЕВОГО БАЗИСА

Резюме. В работе показано, что составляющие личностной подсистемы модели процесса подготовки специалиста позволяют отражать в ней важные аспекты видов профессиональной деятельности, решаемых задач и необходимых компетенций. Поэтому, система сложившихся личностных ценностей является определяющим условием достижения необходимых профессиональных качеств будущего специалиста. При этом, компетентностные составляющие модели деятельности тесно связана с характеристикой внешней среды модели личности. Представлена концептуальная модель, предполагающая адаптивное формирование этапов процесса подготовки специалиста к условиям образовательного процесса, влияющая на содержательные параметры обучения, что, несомненно, определяет такую составляющую модели системы личностных качеств, как степень реализации целей. Для эффективного определения этой модели часто, единственно возможным средством исследования и применения в практических целях знаний об особенностях моделируемых объектов является математическое моделирование, для которого центральным понятием теории математического моделирования является понятие адекватности. Показано, что аргументированная проверка адекватности модели обеспечивает получение добротных и практически значимых результатов. Для определения адекватности нейросетевой математической модели реальному процессу предложено сравнивать полученные в ходе экспериментальных исследований величины с прогнозами при определенных параметрах процесса. Авторами работы удалось установить взаимосвязь между обучающими и тестовыми множествами при создании адекватных моделей объектов различной природы с учетом наилучшего сочетания полноты-точности создаваемой модели с одной стороны и ее простоты с другой. Это выполнено путем проведения оценок точностиадекватности нейросетевых моделей на основе варьирования случайных выборов учебных и тестовых подмножеств, сформированных из одного и того 
ISSN 2077-1827. Гуманізація навчально-виховного процесу. 2019, №. 6 (98)

РОЗДІЛ. ВИЩА ШКОЛА

же массива доступных данных,. В работе доказано, что для нейросетевых моделей адекватность и точность достигаются при $30 \%$ доле тестовой множества. С учетом этого предложено адаптивную модель процесса подготовки специалиста.

Ключевые слова: компетентность, личностные ценности, педагогические технологии, нейронные сети, адекватность моделирования, система.

\section{KOSHEVA Ludmila}

Candidate of Pedagogic Sciences (PhD), Associate Professor, Associate Professor at the Department of Physical Education and Sports, Donbass State Engineering Academy

st. Academic, 72, Kramatorsk, Donetsk region, Ukraine, 84313

E-mail: kosheva@,i.ua

\section{KOVALEVSKYY Sergiy}

Doctor of Technical Science, Professor, Head at the Department of Engineering Technology, Донбаська державна машинобудівна академія

st. Academic, 72, Kramatorsk, Donetsk region, Ukraine, 84313

E-mail: kovalevskii@dgma.donetsk.ua

\section{KOVALEVSKA Olena}

Candidate of Technical Sciences (PhD), Associate Professor, Associate Professor at the Departments of Computer-aided Design and $\mathrm{M}$ odeling of Processes and Machines, Donbass State Engineering Academy

st. Academic, 72, Kramatorsk, Donetsk region, Ukraine, 84313

E-mail: olenakovalevskaya@gmail.com

\section{COMPETENCE - VALUE MODELING USING A NEURAL NETWORK BASIS}

Summary. The authors of the article present the features of creating poorly formalized models, reflecting the competence approach, which allows monitoring the formation of the necessary competencies of the future specialist in the light of changes in his personal values. It is shown that quantitative neural network modeling of competence and value models is an effective tool for monitoring and managing the processes of formation of specialists, taking into account their individual characteristics and stakeholder requests. For this purpose, the optimal formation of training and test sets of neural network models is proposed.

Keywords: competence, personal values, pedagogical technologies, neural networks, modeling adequacy, system.

Abstract. Introduction. The authors of the article present the features of creating poorly formalized models, reflecting the competence approach, which allows monitoring the formation of the necessary competencies of the future specialist in the light of changes in his personal values. 
Analysis of publications. Taking into account the individual characteristics of students, solving educational problems, taking into account the interests of students, diversity, novelty, emotional class, as well as general cultural level, erudition, scientific and methodological preparation, responsibility, hard work, conviction, reasonable demand, pedagogical ensure the quality of the educational process. For the success of the educational process, it is important to have an attitude towards the formation of competencies of future specialists, based on the internal needs, motives of students, as well as on the set of acquired knowledge, skills and professional skills. The purpose of preparation and the set of psychological and pedagogical instructions allowed to form the content of specialist training, certain requirements for professionalism, as well as the value system of the specialist's coordinates.

Purpose. The main purpose of the article is to substantiate ways of improving the adequacy of mathematical models, built on a neural network basis, reflecting the processes of formation of competencies and values of future specialists.

Results. The central concept of modeling theory is the concept of adequacy. Purpose of the study: to establish the relationship between training and test sets when creating adequate models of objects of different nature. The neural network based approach is a mathematical construct with a variable structure that depends on the input. The adequacy of such models is verified on the basis of satisfactory testing on a test set which is not included in the training set, and the volume of the output data sets is directly related to the quality of the models formed on the basis of these data.

The minimum of the total error estimated against randomly formed subsets occurs when establishing the test set as $1 / 3$ of the randomly selected portion of the total data set used for the simulation. Such a recommendation is certainly different from the $80 \% / 20 \%$ recommendation and should be taken into account when building neural networks.

Conclusion. Training professionals as a system of pedagogical technologies influences the formation of motives for success. Therefore, it is of great importance to identify methods for managing the complex of personal qualities of students in the group of specialists through the construction and use of adequate neural network models. Assessment of the degree of achievement of results in the formation of necessary competencies leads to the need for timely correction of educational technology. Only sufficient motivation, based on spiritual, social and physical education (culture education) and the needs of the student's personality (model of student's personality), can really form such professional qualities of a specialist, which will allow to ensure the adequacy of a trained specialist through his professional activity.

\section{REFERENCES}

1. Dyba T.H. (2015). Fenomen neperervnoi profesiinoi osvity u dosiahnenni profesiinoho «akme». Osvitolohiia, 4, 30-36. (in Ukr.). 
ISSN 2077-1827. Гуманізація навчально-виховного процесу. 2019, №. 6 (98)

РОЗДІЛ. ВИЩА ШКОЛА

2. Bibik I.M. at al. (2004). In O. V. Ovcharuk (Ed.). Kompetentnisnyi pidkhid u suchasnii osviti: svitovyi dosvid ta ukrainski perspektyvy: kolektyvna monohrafiia. Kyiv: K.I.S. (in Ukr.).

3. Ohneviuk V.O. (2003). Osvita v systemi tsinnostei staloho liudskoho rozvytku: monohrafiia. Kyiv: Znannia Ukrainy. (in Ukr.).

4. Osvitolohiia: pidhotovka ekspertiv u haluzi osvity. (2015). InV.O. Ohneviuk (Ed.). Kyiv: TOV VP Edelveis. (in Ukr.).

5. Kozakov V.A. at al. (2003). In V.A. Kozakov (Ed.). Psykholohiia diialnosti ta navchalnyi menedzhment. Kyiv: KNEU. (in Ukr.).

6. Yermakov I.H. (2003). Fenomen kompetentnisno spriamovanoi osvity. Krok za krokom do zhyttievoi kompetentnosti ta uspikhu. Kyiv: LAT \& K. (in Ukr.).

7. Kabankova O.M. (2015). Deiaki aspekty akmeolohichnoi kompetentnosti maibutnoho fakhivtsia. Problemy osvity: zbirnyk naukovykh prats. Zhytomyr - Kyiv: Vyp. 84.148-151. (in Ukr.).

8. Kovalevskyy S.V., Kosheva L.V. (2015). Study ofthe Nature and Structure of Corporate Culture with Neural Network Models. American Journal of Neural Networks and Applications. New York, 1. 1. 11-22. : 10.11648 /j.ajnna.20150101.12

9. Kovalevskyy S.V., Kosheva L.V. (2015). Research the Corporate Culture of Students Using Neural Network Models. American Journal of Neural Networks and Applications. New York,1. 2. 43-47. : 10.11648/j.ajnna.20150102.13

10.Kaladze V.A. (2012). Mathematical models of casual processes with stationary increments and the non-uniform information dynamic processing: Monograph. Lorman, MS, USA: Science Book Publishing House.

11. Gantseva E.A., Kaladze V.A., Poliakov A.M. (2013). Intellektualnyi kriterii kachestva matematicheskikh modelei slozhnykh sistem: ideologiia, perspektivy razrabotki. Vestnik Voronezhskogo gosudarstvennogo tekhnicheskogo universiteta, 9(5.1). 52-56. (in Rus.).

12. Kovalevskyy S., Kosheva L. (2012). Neural network's intellectual model of student. Proceedings of 12th International conference "Research and Development in Mechanical Industrry" RaDMI 2012, Vrnjcka Banja, Serbia, 2012. [CD ROM].

(переклад зроблено С. Ковалевським - д.т.н., професором, завідувачем кафедри технології машинобудування ДДМА) 